\title{
Managing Risks in the Improved Model of Rolling Mill Loading: A Case Study
}

\author{
Nelli Vladimirovna Syreyshchikova ${ }^{1}$, Danil Yurievich Pimenov ${ }^{1, *(D)}$, Elena Nikolaevna Yaroslavova ${ }^{2}$,

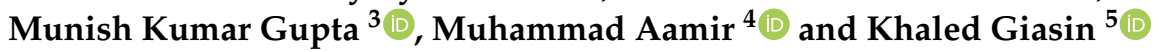

1 Department of Automated Mechanical Engineering, South Ural State University, Lenin Prosp. 76, 454080 Chelyabinsk, Russia; snv.ktn@mail.ru

2 Department of Foreign Languages, South Ural State University, Lenin Prosp. 76, 454080 Chelyabinsk, Russia; yaen@bk.ru

3 Faculty of Mechanical Engineering, Opole University of Technology, 45-758 Opole, Poland; munishguptanit@gmail.com

4 School of Engineering, Edith Cowan University, Joondalup, WA 6027, Australia; m.aamir@ecu.edu.au

5 School of Mechanical and Design Engineering, University of Portsmouth, Portsmouth PO1 3DJ, UK; Khaled.giasin@port.ac.uk

* Correspondence: danil_u@rambler.ru

Citation: Syreyshchikova, Nelli Vladimirovna, Danil Yurievich Pimenov, Elena Nikolaevna Yaroslavova, Munish Kumar Gupta, Muhammad Aamir, and Khaled Giasin. 2021. Managing Risks in the Improved Model of Rolling Mill Loading: A Case Study. Journal of Risk and Financial Management 14: 359. https://doi.org/10.3390/jrfm14080359

Academic Editor: Cristina Raluca Gh. Popescu

Received: 27 May 2021

Accepted: 2 August 2021

Published: 6 August 2021

Publisher's Note: MDPI stays neutral with regard to jurisdictional claims in published maps and institutional affiliations.

Copyright: (c) 2021 by the authors. Licensee MDPI, Basel, Switzerland. This article is an open access article distributed under the terms and conditions of the Creative Commons Attribution (CC BY) license (https:// creativecommons.org/licenses/by/ $4.0 /)$

\begin{abstract}
This article reflects the main sources of risks for metallurgical enterprises in Russia, presenting the implementation of an innovative approach to increasing the competitiveness of an industrial enterprise, which is a typical representative of large enterprises of the metallurgical industry, based on the development of risk-oriented thinking when loading rolling mills with orders of intersecting assortment according to a new model. To reduce the emerging risks of a new model of the loading process of rolling mills of a metallurgical enterprise, it is proposed to take into account the risks in a complex way, taking into account their interactions with the use of integrated risk management (IRM). Practical development of the implemented approach was carried out by identifying the risks of the new improved loading process and their causes at each stage of the process. Risks were identified by analysis, qualitative and quantitative assessment of the likelihood of risks and the severity of consequences from their implementation with the establishment of events with a high potential hazard. Possible causes of hazardous events have been identified. To reduce the likelihood of unfavorable events, measures have been developed to influence significant risks and their effectiveness has been determined. The development of an innovative approach using risk-based thinking in a previously unexplored field of the application provides competitive advantages for enterprises of the metallurgical industry, increases income by reducing the cost of manufacturing products and production volumes by reducing time costs, achieving an economic efficiency of up to 10 million rubles per year. The practical significance of the dissemination of development results in similar industries is obvious and relevant for metallurgy as a whole.
\end{abstract}

Keywords: loading model improvement; risk management; rolling mill; orders with overlapping stock; mastering

Investing in the prevention of risks, defects, or non-conformances, we save on the control costs, and in particular, on the costs of defects elimination.

\section{—Walter A. Shewhart}

\section{Introduction}

Russian metallurgical enterprises have long been among the world leaders in their industries. In recent years, global (including Russian) metallurgy has been subject to the same constant risks: resource nationalism, implying a tendency to increase taxation and an increase in the degree of government participation in the industry, a lack of qualified personnel, a lack of sufficiently developed railroad networks, an increase in the influence of 
public opinion on the activities of metallurgical companies, etc. Among these typical risks for the present time, international rating companies distinguish such a financial risk as to the volatility of currency risks, which has a very large impact on the level of costs. In Russia, oil companies and Gazprom were the first to show attention to risk management. Then, the risk management system was introduced by other export-oriented companies, including metallurgical ones. For the latter, the traditionally decisive importance was not financial, but production risks. Unfortunately, the problem became significant for them only after the onset of force majeure. Hence, there is a significant lag behind their Western counterparts and, again, a significant number of mistakes made. Many researchers have written about insufficient attention in Russia to the problem of risks (Kazakova and Kogdenko 2021). However, in principle, risks have always been and remain one of the essential issues of any branch of the metallurgical industry in any country (Razuvaev 2016).

As Schumpeter et al. (2017) reflected in their works, competition and innovation are the engines of economic progress. Organizations of all types and sizes face internal and external factors and impacts, which cause uncertainty. The goals of an enterprise may cover various aspects of its activities: from the strategy to the production of goods (Siferd and Smeltzer 1998; Tayal et al. 2021), to process (Shojaei and Haeri 2019; Syreyshchikova et al. 2020a) and project development (Verma and Sinha 2020). The influence of uncertainty on an organization's goals is a risk, in essence. To achieve confidence in reaching the planned result, risk management is necessary (Prakash et al. 2017). Using the risk-based thinking at enterprises with a quality management system (QMS) in action (and when planning its activity) is one of the direct requirements under the new revision of the ISO 9001:2015 international standard (Enders et al. 2017) and the GOST R ISO 9001-2015 national standard (GOST R ISO 9001 2015). Risk-based thinking ensures that the confidence in those risks is revealed, considered, and managed in the course of designing, implementing, and improving QMS at an enterprise (Veena and Prabhushankar 2019).

That is why risk management is currently one of the most relevant fields of activity of industrial enterprises. Since competition in the domestic and foreign markets is increasing, each enterprise, and even more so in the metallurgical industry, needs to reduce the likelihood of events that can adversely affect the achievement of the set goals, which is what these studies are devoted to. Until now, we still cannot state that the study of the process of risk management has been performed in full and is complete. It is generally believed that it began with an idea by the Swiss mathematician Daniel Bernoulli, who back in 1738, amended the theory of probability with a method of usefulness or attractiveness of this or that event outcome and insisted that in the process of making decisions, people pay more attention to the scale of the consequences of various outcomes, rather than to their probability (Bernoulli 1954). Late in the 19th century, a polymath from England, Francis Galton, proposed to consider regression or reversion toward the mean to be a universal statistical pattern. According to the researcher, regression in its essence is a return of phenomena to their normal state over time. Subsequently, it was proven that the rule of regression is true for the most various situations, from gambling and calculating the probability of accidents to predicting the fluctuations of economic cycles.

In 1952, a doctoral student at the University of Chicago, Harry Markowitz, in his article "Portfolio Selection", presented a mathematical explanation of the strategy of investment portfolio diversification; in particular, he demonstrated how through a well-thought-out distribution of investments, it would be possible to minimize the deviation of return from the expected indicators. In 1990, Harry Markowitz was awarded the Nobel Prize for elaborating the theory and practice of optimizing a security assets portfolio (Markowitz 1952). Today, developments in risk management theory are built upon three basic concepts: utility, regression, and diversification. The risk management terminology itself was coined for the first time about 50 years ago, while the practical application of risk management originated in the field of insurance in the context of insurance coverage purchasing by beneficiaries (Padanyi 1971; Samson 1987). At present, there exists a significant number of works on the practical use of risk management in various fields: in construction (Mills 2021), 
transportation (Curtis et al. 2012), energy (Scott and Perry 2012), and food industries (Prata et al. 2020), in tourism and services (Healy et al. 2020), in the financial sector (Ghasemi and Ghasemi 2020), education (Syreyshchikova et al. 2020b; Ulven and Wangen 2021), investment business (Uuskoski et al. 2020), and entrepreneurship (Andreeva 2021), and over the recent decade, in nanotechnology (Lee et al. 2010), the information sphere (Kondratyeva et al. 2021), and information safety (Syreyshchikova et al. 2019). Practically no works have been written on the application of risk management in such an economically important sector as the metallurgical industry. Currently, risk terminology has been streamlined in the new ERM standard (FERMA (Federation of European Risk Managers Associations)); and the experience of applying the ERM standard by non-financial companies on changes in risk management methods is reflected in the works on the complexity of the approach in ERM (Bertinetti et al. 2013; Anton 2018). Additionally, in (Anton 2013) is given the experience of analyzing the practice of risk management for Romanian metallurgical companies. The experience of reducing the risks of equipment manufacturers and their users at metallurgical enterprises is presented in (Małysa et al. 2016). An interesting experience in the analysis and identification of the determining factors of the quality of steel products at the selected Polish enterprise (Czajkowska and Stasiak-Betlejewska 2016). Methods of risk reduction in work are recommended for use at metallurgical enterprises (Goncharenko et al. 2016); and the development of risk management in the metallurgical industry of the Russian Federation is currently moderate against the global background, but significant in comparison to other industries in Russia. However, there is not enough work on the practical use of risk management in such an important industry for the economy as metallurgy. Thus, the relevance of the study on the development of a risk management system for rolling mills for the conditions of a metallurgical enterprise is justified. That is why the relevance of this research on developing risk management for rolling mills at an iron and steel enterprise is well-reasoned.

For the "Kranovye technologii" (Crane Technologies) metallurgical enterprise, the improvement of its competitiveness is also relevant. Jointly with the Department of Automated Manufacturing Engineering of South Ural State University (SUSU), the enterprise has performed research and development work (R\&D) to improve the efficiency of the enterprise's activity through developing risk management procedures for successful mastering of a created new optimal model of loading the enterprise's production sites. The model implies rational distribution of the orders with overlapping stock to reduce the probability of unfavorable events for a previously not-studied field of application at a metallurgical enterprise.

R\&D tasks are as follows: determining the situation on the process of rolling mill loading with orders with overlapping stock as per the improved model; selecting the risk management methods; identifying the possible events and their causes (risk identification); identifying the consequences of these events with regard to the loading process; determining the probability of such events; revealing the factors which may reduce the unfavorable consequences or decrease the probability of hazardous situations; selecting the methods of analyzing and assessing the process risks; analyzing and assessing the loading risks; revealing the most significant risks; developing the measures on minimizing the revealed risks, and evaluating the efficiency of implementing those concerning the rolling mill loading with orders with overlapping stock as per the improved model.

The scientific novelty of the work is as follows. To reduce the emerging risks of a new model of the loading process of rolling mills of a metallurgical enterprise, it is proposed to take into account the risks comprehensively, taking into account their interrelationships, not concentrating on one type of risk, but considering all possible risks, i.e., applying so-called integrated risk management (IRM) or enterprise risk management (ERM; or enterprise-wide risk management, I'WRM). For a typical ferrous metallurgy enterprise, the aim was to develop recommendations for minimizing enterprise risks. 


\section{Process Theory}

Based on the analysis of the research studies in the field of risk management, and with consideration to modern requirements, the method of risk management should comply with the following principles:

- A decision under risk should be economically adequate and should not affect the results of the financial and economic activity of an enterprise.

- Risk management should be fulfilled within the corporate strategy of the enterprise.

- In risk management, the decisions made should be based on the required volume of authentic information.

- During risk management, the decisions made should consider the objective characteristics of the environment, in which the enterprise carries out its activities.

- Risk management should be systemic.

- Risk management should imply the analysis of the current effectiveness of the decisions made, as well as the prompt correction of the set of the risk-management principles and methods being used.

The risk management process is illustrated in Figure 1, where $\mathrm{R}$ is the risk level, and $\mathrm{Rd}$ is the acceptable level of risk (Ponomarev 2016).

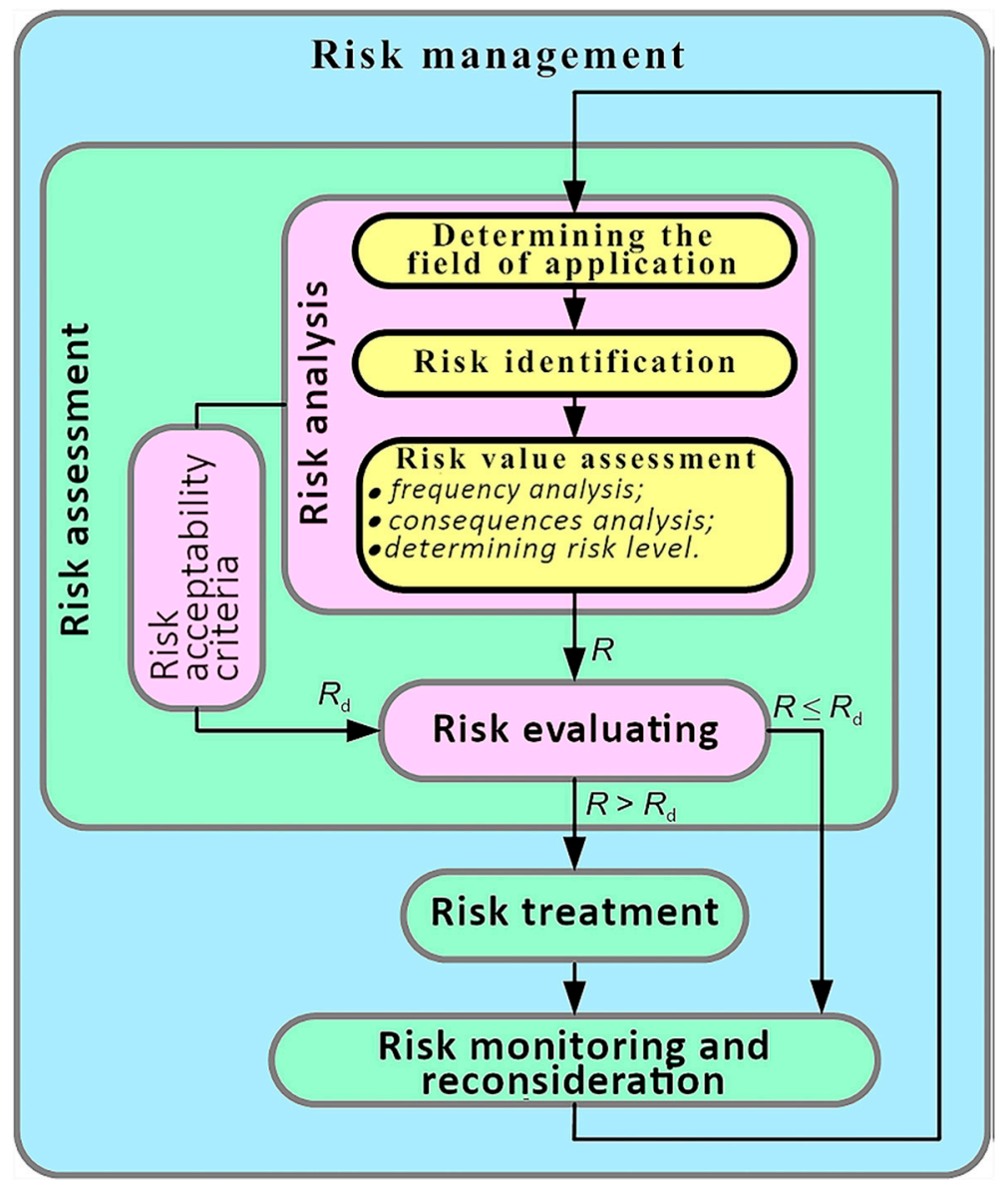

Figure 1. Risk management process.

In the process of risk management, a crucial part is the documenting of its separate stages. The documenting of the stage of risk assessment is important because it is usually executed in the form of a risk assessment report. Documenting the risk assessment allows further use of the accumulated information for risk treatment, estimation of the costs of risk reduction, and several other factors. The interconnection between the main stages of risk management is shown in Figure 2 (Ponomarev 2016). 


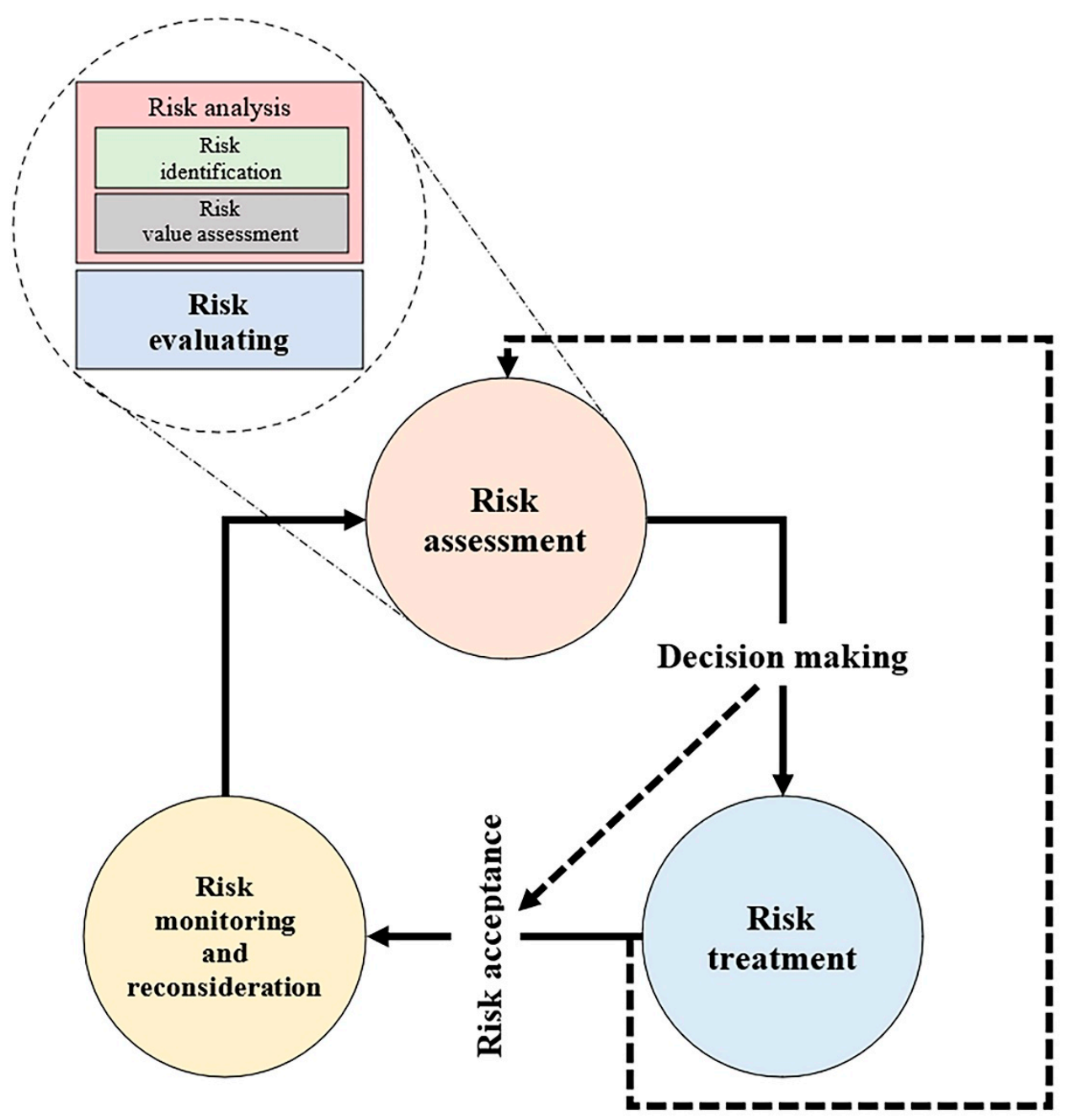

Figure 2. Interconnection between the risk management stages.

The base stage that helps form the risk management strategy is the stage of risk assessment. The main part of the risk assessment stage is the procedure of risk analysis, which holds a special place in the process of risk management and determines the effectiveness of risk reduction. The scheme of the connection between risk analysis and risk reduction is given in Figure 3 (Mamaeva 2013).

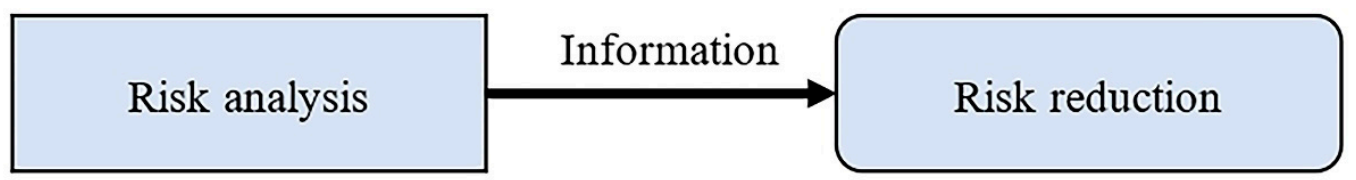

Figure 3. Interconnection between analysis and reduction of risk.

When assessing the efficiency of taking the measures planned with regard to the risk parameters, it is necessary to:

- Forecast unfavorable events and give scientific justification for risk assessment while taking the measures planned, both for each separate one and for all of them integrally.

- Give scientific justification for the assessment of critical (unacceptable) risks.

- Determine the levels of tolerable (acceptable) risks adopted based on the set task.

- Manage the technical and technological development with consideration to the requirements of security as per the risk criteria. 


\section{Experimental Research}

To develop the risk management for the process of loading the production sites of the enterprise using the new model, it has been necessary to fulfill the following stages: (1) determining the situation, (2) evaluating the risk, including risk identification, risk analysis and assessment, and (3) risk treatment (Ionova and Syreyshchikova 2019). The methods for fulfilling each stage of the risk management under development have been considered (GOST R ISO/IEC 31010 2012), and the methods most suitable for the essence of the subject of study have been chosen for the use, as well as the methods which in combination cover all the stages of risk assessment. Following the results of comparing and contrasting the input and output data, the action execution sequence, and the advantages and disadvantages of the studied methods of risk identification, the Hazard and Operability method (HAZOP) has been chosen since its application ensures a systematic and more complete investigation of the process of rolling mill loading with orders with overlapping stock (Ionova and Syreyshchikova 2019). The risks of the process of "Developing a Model of Rolling Mill Loading with Orders with Overlapping Stock" have been identified. The following has been determined for each risk: cause, risk factors, classification group (criterion, risk area), and potential consequences (with an indication of the control words under the chosen method of identification). The elaborated risk register is given in Table 1.

Table 1. Register of the risks for the process of "Developing a Model of Rolling Mill Loading with Orders with Overlapping Stock".

\begin{tabular}{|c|c|c|c|c|c|}
\hline Control Word & Risk & Cause & Risk Factor & $\begin{array}{l}\text { Classification } \\
\text { Group }\end{array}$ & Consequence \\
\hline \multicolumn{6}{|c|}{1 Determining the overlapping stock } \\
\hline \multirow{2}{*}{$\begin{array}{l}\text { "Not or no", } \\
\text { "Other" }\end{array}$} & \multirow{2}{*}{$\begin{array}{l}\text { Overlapping stock not determined or } \\
\text { determined incorrectly }\end{array}$} & No control & $\begin{array}{l}\text { Management } \\
\text { errors }\end{array}$ & $\begin{array}{l}\text { Organizational } \\
\text { factor }\end{array}$ & \multirow{2}{*}{$\begin{array}{l}\text { Model not created or } \\
\text { created incorrectly }\end{array}$} \\
\hline & & Analysis errors & Human factor & Social factor & \\
\hline "Less (lower)" & Overlapping stock determined not fully & Analysis errors & Human factor & Social factor & Model errors \\
\hline \multicolumn{6}{|c|}{2 Distributing the overlapping stock } \\
\hline "Not or no" & $\begin{array}{l}\text { The distribution criterion is insufficient } \\
\text { or redundant }\end{array}$ & $\begin{array}{l}\text { No understanding of } \\
\text { the process }\end{array}$ & Human factor & $\begin{array}{l}\text { Organizational, } \\
\text { social factors }\end{array}$ & Model errors \\
\hline "Part" & Collected data are incomplete & $\begin{array}{l}\text { Wrong task setting; } \\
\text { Lack of authority }\end{array}$ & $\begin{array}{l}\text { Management } \\
\text { errors }\end{array}$ & $\begin{array}{l}\text { Organizational } \\
\text { factor }\end{array}$ & $\begin{array}{l}\text { The model does } \\
\text { not reflect the } \\
\text { actual situation }\end{array}$ \\
\hline "Same as" & $\begin{array}{l}\text { Use of different methods, or criteria of } \\
\text { calculations by specialists from different } \\
\text { plants when providing similar data }\end{array}$ & $\begin{array}{l}\text { Each plant has its methods } \\
\text { developed and used }\end{array}$ & $\begin{array}{l}\text { Management } \\
\text { errors }\end{array}$ & $\begin{array}{l}\text { Organizational } \\
\text { factor }\end{array}$ & Model errors \\
\hline "Not or no" & Calculation errors during the analysis & Employee carelessness & Human factor & Social factor & Model errors \\
\hline "Not or no" & Model not created & $\begin{array}{l}\text { No control from } \\
\text { the supervisor }\end{array}$ & $\begin{array}{l}\text { Management } \\
\text { errors }\end{array}$ & $\begin{array}{l}\text { Organizational } \\
\text { factor }\end{array}$ & Model not created \\
\hline \multicolumn{6}{|c|}{3 Standardization } \\
\hline "Not or no" & $\begin{array}{l}\text { No agreement of the obtained results with } \\
\text { the key persons }\end{array}$ & $\begin{array}{l}\text { Workshop specifics not } \\
\text { taken into account during } \\
\text { the development }\end{array}$ & $\begin{array}{l}\text { Management } \\
\text { errors }\end{array}$ & $\begin{array}{l}\text { Organizational } \\
\text { factor }\end{array}$ & $\begin{array}{l}\text { Model is not used } \\
\text { in work }\end{array}$ \\
\hline "Other" & Work results not documented & $\begin{array}{c}\text { No control. } \\
\text { Lack of resources }\end{array}$ & $\begin{array}{l}\text { Management } \\
\text { errors }\end{array}$ & $\begin{array}{l}\text { Organizational } \\
\text { factor }\end{array}$ & Model is no longer used \\
\hline \multicolumn{6}{|c|}{4 Risks related to the use of the developed model } \\
\hline “Not or no" & The developed model is not used in work & $\begin{array}{c}\text { No control. } \\
\text { The model is not } \\
\text { documented. } \\
\text { Work performers are not } \\
\text { aware of the results of work }\end{array}$ & $\begin{array}{l}\text { Management } \\
\text { errors }\end{array}$ & $\begin{array}{l}\text { Organizational } \\
\text { factor }\end{array}$ & $\begin{array}{l}\text { Model is not used in } \\
\text { work, and its goals are } \\
\text { not being achieved. }\end{array}$ \\
\hline
\end{tabular}

Qualitative assessment of the risks of the process of "Developing a Model of Rolling Mill Loading with Orders with Overlapping Stock" has been carried out, and the consequences, probability, and level of risk have been determined as per the scale "high", "medium", and "low", and per the criteria presented in Tables 2 and 3. The results of the qualitative assessment of the risks and the consequences of the risks for the process are given in Tables 4 and 5 . 
Table 2. Qualitative assessment of event probability.

\begin{tabular}{ccc}
\hline Probability Estimate & Description & Indicators \\
\hline High (probable) & Event probability exceeding 25\% & The potential probability that there will be several occurrences of \\
the event over a certain period
\end{tabular}

Table 3. Qualitative assessment of event consequences.

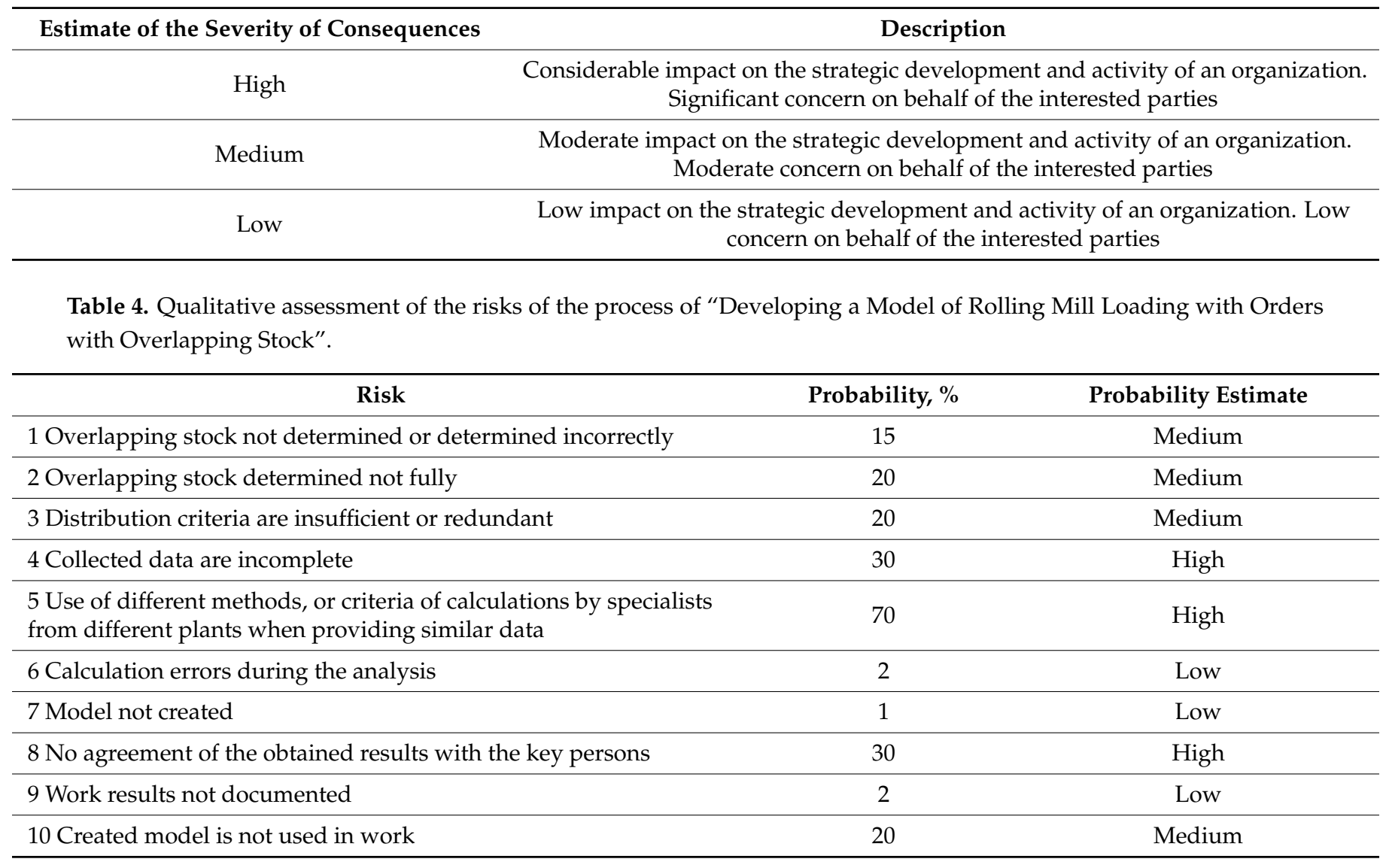

Table 5. Qualitative assessment of risk consequences.

\begin{tabular}{lc}
\hline \multicolumn{1}{c}{ Risk } & Level of Consequences \\
\hline 1 Overlapping stock not determined or determined incorrectly & Medium \\
\hline 2 Overlapping stock determined not fully & Medium \\
\hline 3 Distribution criteria are insufficient or redundant & Medium \\
\hline 4 Collected data are incomplete & Medium \\
\hline $\begin{array}{l}\text { 5 Use of different methods, or criteria of calculations by specialists from different } \\
\text { plants when providing similar data }\end{array}$ & Medium \\
\hline 6 Calculation errors during the analysis & High \\
\hline 7 Model not created & High \\
\hline 8 No agreement of the obtained results with the key persons & Medium \\
\hline 9 Work results not documented & High \\
\hline 10 Created model is not used in work & \\
\hline
\end{tabular}


The analysis of the qualitative assessment of the risks of the process of "Developing an Optimal Model of Rolling Mill Loading with Orders with Overlapping Stock" has demonstrated that situations 4,5 , and 8 are hazardous risks as they are characterized with high probability and high severity of consequences.

To conduct the quantitative assessment of the risks, the method of Hazard Analysis and Critical Control Points (HACCP) has been chosen. Risk level (R) has been calculated as per the following formula (ISO 22000:2018 2018):

$$
\mathrm{R}=\mathrm{O} \times \mathrm{S} \text {, score, }
$$

where $\mathrm{O}$ is the hazardous factor probability, score; $\mathrm{S}$ is the severity of the consequences from the hazardous factor, score. The results of identifying the hazards, which could affect the achievement of the planned results, as well as the score estimates for risk indicators $\mathrm{O}, \mathrm{S}$, and risk level $\mathrm{R}$ when assessing the risks of the process of "Developing a Model of Rolling Mill Loading with Orders with Overlapping Stock", are presented in Table 6.

Table 6. Results of assessing the indicators of the risks of the process under study.

\begin{tabular}{lllc}
\hline \multicolumn{1}{c}{ Risk } & O, Score & S, Score & R, Score \\
\hline 1 Overlapping stock not determined or determined incorrectly & 2 & 4 & 8 \\
\hline 2 Overlapping stock determined not fully & 2 & 2 & 4 \\
\hline 3 Distribution criteria are insufficient or redundant & 2 & 2 & 4 \\
\hline 4 Collected data are incomplete & 3 & 3 & 9 \\
\hline $\begin{array}{l}\text { 5 Use of different methods, or criteria of calculations by } \\
\text { specialists from different plants when providing similar data }\end{array}$ & 1 & 4 & 3 \\
\hline 6 Calculation errors during the analysis & 1 & 3 \\
\hline 7 Model not created & 2 & 3 \\
\hline 8 No agreement of the obtained results with the key persons & 1 & 4 \\
\hline 9 Work results not documented & 2 & 3 \\
\hline 10 Created model is not used in work & 3 & 8 \\
\hline
\end{tabular}

The result of analyzing the risks of the process of "Developing a Model of Rolling Mill Loading with Orders with Overlapping Stock" is given in Figure 4. Risk analysis as per the diagram (see Figure 4) has shown that events 2, 3, 4, 6, and 9 are in the region of acceptable risks, while events $1,5,7,8$, and 10 are in the region of unacceptable risks. Thus, it has been determined that events $1,5,7,8$, and 10 will have the most hazardous risks for the process of "Developing a Model of Rolling Mill Loading with Orders with Overlapping Stock". Event No. 7, "Model not created", is a risk related to not achieving the set goal of the project in progress, so this means that this is the most unfavorable and undesirable risk. Events 1-8 are what caused this risk. Event No. 10, "Created model is not used in work", is also unfavorable as it means that the time and effort spent on the creation of this model were wasted. Further analysis of events No. 7 and No. 10 included building a fault tree and performing a cause-and-effect analysis.

To identify and analyze the factors, which may bring along the unfavorable event No. 7, "Model not created/Created model does not reflect the actual situation", understudy, as well as to determine their probability, a fault tree has been built (see Figure 5). The analysis of the data from the chart in Figure 5 demonstrates that the risk is caused by human and organizational factors.

To find out the causes of the unfavorable event No. 10, "Created model is not used in work", a cause-and-effect analysis has been performed based on the data obtained using the brainstorming method. The result of applying this method is shown in Figure 6. 


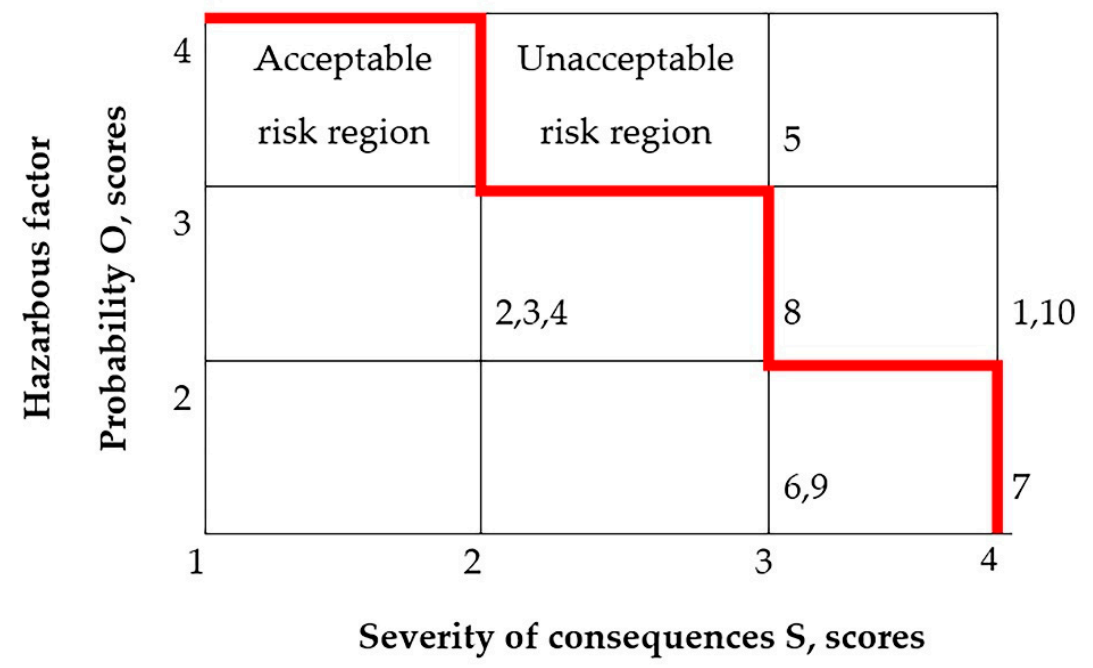

Figure 4. Diagram of analyzing the risks of the process of "Developing a Model of Rolling Mill Loading with Orders with Overlapping Stock".

The analysis of the occurrence of event No. 10 has demonstrated that the risk is caused by human and organizational factors. The human factor includes risk in human resources (lack of competencies and knowledge) and behavioral risk. Behavioral risks occur in the process of activity, are subjective, and are related to the psychological make-up of an individual. Among the peculiarities of behavioral risks are their unpredictability; difficulty to reveal them; subjectivity; and impossibility to evaluate their consequences beforehand. The factors causing behavioral risks include psychological make-up of a certain individual (related to the person's temperament); dissatisfaction with work (working conditions), pay level, as well as the moral and psychological climate in the work team; ineffective management of the organization and the personnel. Methods that are used to assess behavioral risks have been recommended: psychological and qualitative methods (GOST R ISO/IEC 31010 2012).

The qualitative and quantitative analyses have shown the need to manage the risks under No. 7 and No. 10 (model not created/created model does not reflect the actual situation, created model is not used in work). For both these events, the human and organizational factors are the cause of risks. To decide on taking actions aimed at reducing the risk probability, a comparative analysis has been performed of the cost of the risks (actual losses due to the occurrence of a risk situation and expenses on the compensation for these losses) and the preventive actions. For the risks that require managing, it was necessary to develop measures on lowering the level of risk. The measures on risk minimization will allow one to eliminate the risk or bring its level to the minimum. The planned measures of risk treatment have been elaborated. The list of these measures is given in Table 7 with the indicated evaluation of their effectiveness. The costs for the types of activity of the Life Cycle Assessment (LCA) have been determined, i.e., for the production of rolling mills (before, during, and after the development of a new model of loading rolling mills) to determine the rationality and effectiveness of the planned measures to influence risks (Finnveden et al. 2009; Syreyshchikova et al. 2021a, 2021b). To determine the effectiveness of the planned minimization measures $(\mathrm{Rm})$, an analytical model has been created:

$$
\mathrm{Rm}=\mathrm{M} / \mathrm{Y} \text {, score }
$$

where $\mathrm{M}$ are the costs of the risk minimization measure, RUR; $\mathrm{Y}$ is the losses from the risk, RUR. Risk minimization measures with Rm lower than 1 are effective, and measures with Rm higher than 1 are not efficient. The analysis of the data in Table 7 allows one to conclude that the described risk minimization measures fall within the range of $0.15-0.25$ scores and are, therefore, considered to be efficient. 


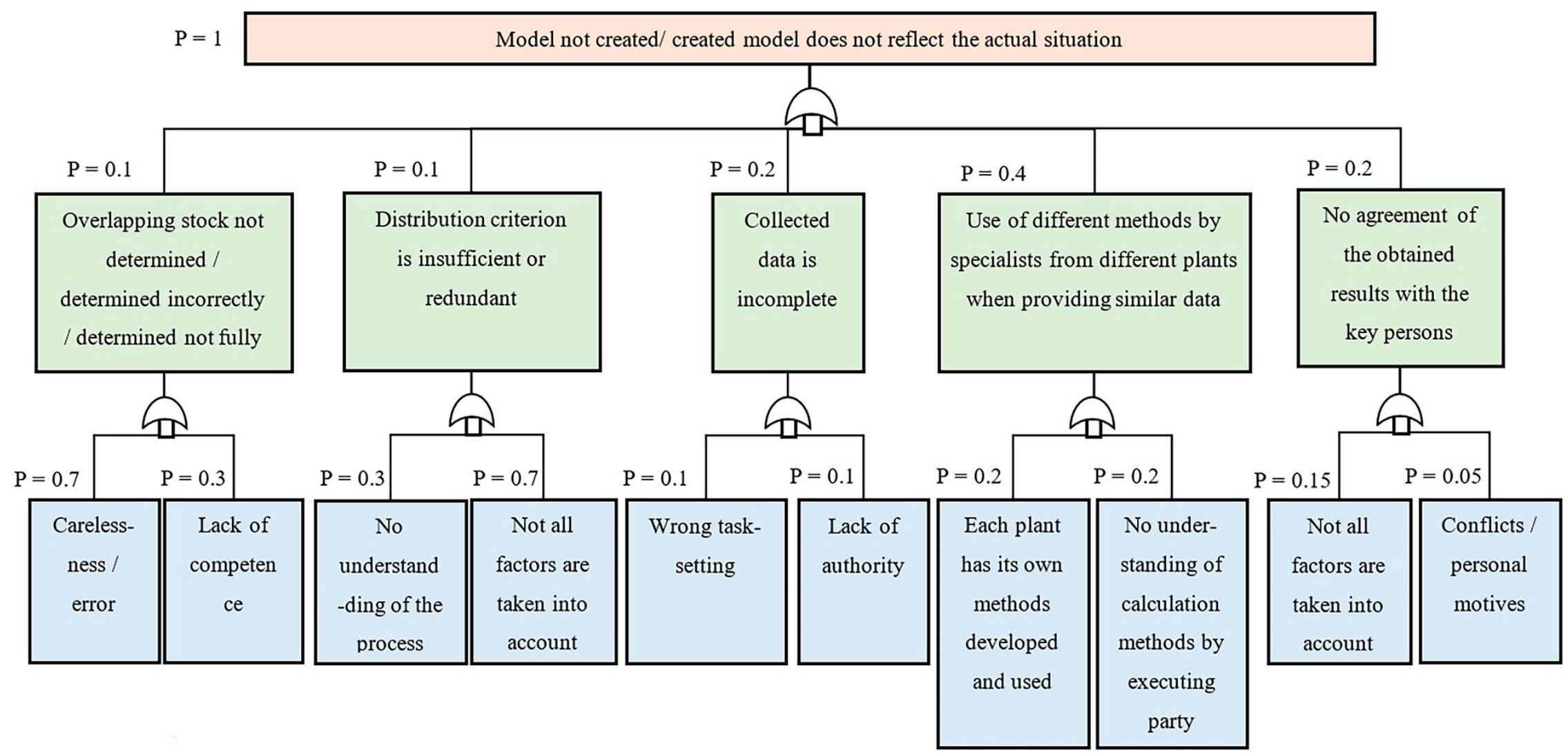

Figure 5. Fault tree for unfavorable event No.7. 


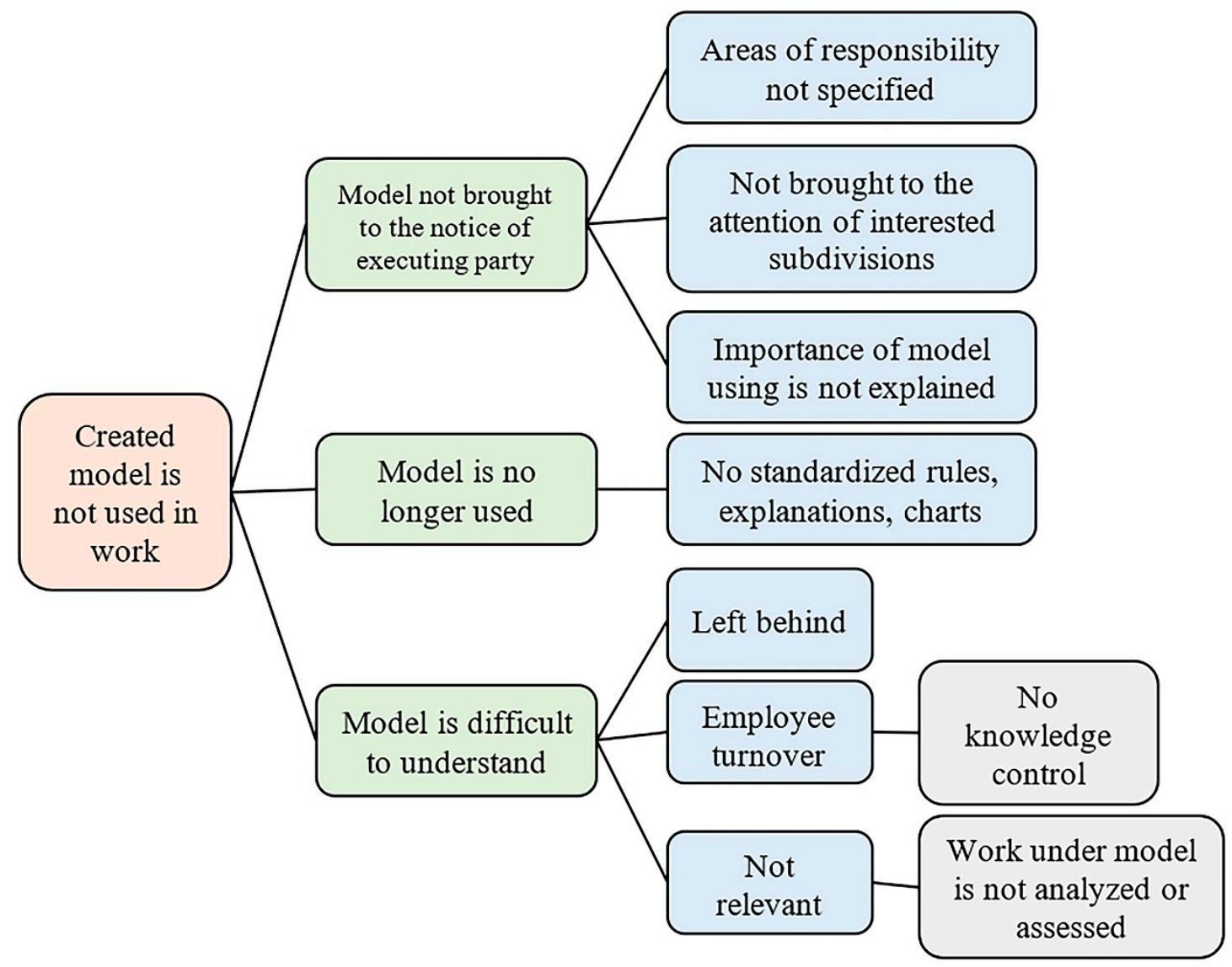

Figure 6. Cause-and-effect analysis for event No. 10.

Table 7. Planned measures on the risk treatment for the process of "Developing a Model of Rolling Mill Loading with Orders with Overlapping Stock" with their effectiveness evaluated.

\begin{tabular}{|c|c|c|c|c|}
\hline Risk & Risk Minimization Measures & Person in Charge & Deadline & Effectiveness \\
\hline \multirow{4}{*}{$\begin{array}{l}\text { Model not } \\
\text { created }\end{array}$} & Clear setting of tasks & \multirow{4}{*}{$\begin{array}{l}\text { Head of the Promising and Foreign } \\
\text { Projects Department }\end{array}$} & \multirow{3}{*}{$\begin{array}{l}\text { Over the whole period } \\
\text { of development }\end{array}$} & $25 \%$ \\
\hline & $\begin{array}{l}\text { Controlling the course of } \\
\text { performing works }\end{array}$ & & & $25 \%$ \\
\hline & $\begin{array}{l}\text { Assistance in case of difficulties when } \\
\text { working with other subdivisions }\end{array}$ & & & $25 \%$ \\
\hline & $\begin{array}{l}\text { Determining the interested parties and } \\
\text { involving them in the wok }\end{array}$ & & $\begin{array}{l}\text { At the first stages of } \\
\text { implementation }\end{array}$ & $25 \%$ \\
\hline \multirow{5}{*}{$\begin{array}{l}\text { Created model } \\
\text { is not used } \\
\text { in work }\end{array}$} & $\begin{array}{l}\text { Obtaining agreement of the gained } \\
\text { results with all the interesting services }\end{array}$ & $\begin{array}{c}\text { Head of the Promising and Foreign } \\
\text { Projects Department }\end{array}$ & \multirow[b]{2}{*}{ At the 3rd stage } & $15 \%$ \\
\hline & Documenting of the obtained results & $\begin{array}{l}\text { Head of the Standardization, } \\
\text { Metrology and } \\
\text { Certification Department }\end{array}$ & & $40 \%$ \\
\hline & $\begin{array}{l}\text { Making the interested subdivisions } \\
\text { aware of the obtained results, explain } \\
\text { the importance of using them in work }\end{array}$ & $\begin{array}{c}\text { Head of the Promising and Foreign } \\
\text { Projects Department }\end{array}$ & At the 3rd stage & $15 \%$ \\
\hline & $\begin{array}{l}\text { Analyzing and assessing the } \\
\text { company's work according to } \\
\text { the model }\end{array}$ & \multirow{2}{*}{$\begin{array}{l}\text { Head of the Standardization, } \\
\text { Metrology and } \\
\text { Certification Department }\end{array}$} & $\begin{array}{l}\text { Monthly over the first six } \\
\text { months, then once every } \\
\text { six months }\end{array}$ & $15 \%$ \\
\hline & Updating the model (when necessary) & & $\begin{array}{l}\text { As per the results of } \\
\text { the analysis }\end{array}$ & $15 \%$ \\
\hline
\end{tabular}




\section{Summary}

The integrated risk management (IRM) of the process of loading the production sites of the enterprise according to the new model was developed: the situation was determined, the risk assessment was carried out, consisting of the identification of risks, analysis, and assessment of risks; the impact on the risks has been carried out. For each stage of the developed risk management, the methods of hazard and operability research "HAZOR" were selected and applied. Identification of risks was carried out and a register of risks of the process "Developing an Optimal Model of Rolling Mill Loading with Orders with Overlapping Stock" was determined. The most dangerous risks with a characteristic high probability and high severity of consequences were identified by the method of qualitative assessment. With a quantitative risk assessment and the "Hazard Analysis and Critical Control Points" method, the level of risks, the probability of hazardous factors, and the severity of consequences from the realization of hazardous factors were calculated. The analysis of the risks of the process was carried out according to the diagram. The events in the zones of acceptable and unacceptable risk were identified. The analysis of the factors contributing to the occurrence of the investigated undesirable events and the determination of their probabilities was carried out using the "fault tree" method. The reasons for the most undesirable events have been clarified. An analytical model for determining the effectiveness $(\mathrm{Rm})$ of the planned measures to minimize and eliminate the risks of the process and the Rm criteria have been created. As the calculation data presented in Table 7 demonstrate, the effectiveness against each unfavorable event is estimated at 0.15 scores to 0.40 scores, which means that to ensure confidence in achieving the required result, the complexity of the planned measures should be fulfilled.

The research results of this work apply to risk management processes when loading production sites of a metallurgical enterprise and apply to similar production processes in ferrous metallurgy.

\section{Conclusions}

In metallurgy in the conditions of market relations, there is an intensification of competition, while it becomes relevant to assess the production risks at enterprises and to develop management solutions that allow influencing of the level of risks in metallurgical production.

- At present, all practical risk management measures are based on the concept of acceptable risk, which consists of striving to reduce risk to a safe level. The idea of integrated risk management is that risks should be considered comprehensively, taking into account their interrelationships. At the same time, risk management should not focus on only one type of risk but must consider all possible risks. In addition, this approach provides a comprehensive view of risk management and a close relationship with other areas of management.

- Risk management should provide a unified system of effective measures to overcome the negative consequences of each element of the entire set of risks, i.e., comprehensively manage the entire set, or portfolio, of risks. The study of the risk portfolio as a whole means that in the study of the risk situation, along with the sources of uncertainty associated with the behavior of individual risks, one more aspect is included: the degree of the relationship between risks.

- The need to consider a large number of risks of a different nature with poorly structured and not always well-understood relationships requires an assessment of all risks based on a single indicator. This reduction of risks to a common basis is called risk aggregation. To highlight specific risks, it is necessary to classify them according to various criteria. The number of possible criteria for classifying risks can be very large, so the classification criteria themselves can be grouped. The choice of specific criteria for the classification of risks depends on the goals and characteristics of the risk management procedure. 
- The scientific novelty of the work consists in increasing the competitiveness of a metallurgical enterprise based on an integrated risk-oriented approach, taking into account the emerging risks in a comprehensive manner and their interrelationships and, as a result, reducing the emerging risks.

- The stages of the new approach have been practically implemented: integrated risk management has been applied, all its stages have been implemented, the risks of the new improved loading process and their causes at each stage of the process have been identified. An innovative approach was implemented to improve the competitiveness and economic efficiency of an industrial enterprise in the metallurgical industry based on the development of risk management in the process of loading rolling mills with orders of intersecting assortment according to a new model. An innovative approach was implemented to improve the competitiveness and economic efficiency of an industrial enterprise in the metallurgical industry based on the development of risk management in the process of loading rolling mills with orders of intersecting assortment according to a new model. The stages of the new approach are practically implemented: the risks of the new improved loading process and their causes have been identified at each stage of the process. Through the analysis, qualitative and quantitative assessment of the likelihood of the occurrence of risks and the severity of the consequences from their implementation, events with a high indicator of potential hazard are identified, and possible causes of hazardous events are identified. To reduce the likelihood of unfavorable events, measures have been developed to influence significant risks with the determination of their effectiveness. The application of an innovative approach using risk-based thinking in a previously unexplored area can increase the company's marginal income by reducing the cost of manufacturing products; increase production volumes by reducing time costs while achieving economic efficiency of up to 10 million rubles per year; and as a result, increase the competitiveness of the metallurgical industry enterprise.

The practical significance of the dissemination of the development results in similar industries is obvious and relevant for metallurgy as a whole.

Author Contributions: Conceptualization, N.V.S. and D.Y.P.; methodology, N.V.S.; software, N.V.S.; validation, N.V.S., D.Y.P., E.N.Y., and K.G.; formal analysis, N.V.S.; investigation, N.V.S.; resources N.V.S.; data curation, N.V.S.; writing—original draft preparation, N.V.S., D.Y.P., E.N.Y., M.K.G., M.A., and K.G.; writing - review and editing, N.V.S., D.Y.P., E.N.Y., M.K.G., M.A., and K.G.; visualization, N.V.S. and D.Y.P.; supervision, N.V.S. and D.Y.P.; project administration, N.V.S. and D.Y.P.; funding acquisition, D.Y.P. and K.G. All authors have read and agreed to the published version of the manuscript.

Funding: This research received no external funding.

Informed Consent Statement: Informed consent was obtained from all subjects involved in the study.

Data Availability Statement: All data generated or analyzed during this study are included in this article.

Conflicts of Interest: The authors declare no conflict of interest.

\section{References}

Andreeva, Tzvetelina. 2021. Risk management in the insurance company. Accounting, Finance, Sustainability, Governance and Fraud, 131-38. [CrossRef]

Anton, Sorin Gabriel. 2013. Who manages financial risk? An empirical examination of risk management practices in the Romanian metallurgical industry. Metalurgija 52: 518-20.

Anton, Sorin Gabriel. 2018. The impact of enterprise risk management on firm value: Empirical evidence from romanian non-financial firms. Engineering Economics 29: 151-57. [CrossRef]

Bernoulli, Daniel. 1954. Exposition of a New Theory on the Measurement of Risk. Econometrica 22: 23-36. [CrossRef]

Bertinetti, Giorgio Stefano, Elisa Cavezzali, and Gloria Gardenal. 2013. The Effect of the Enterprise Risk Management Implementation on the Firm Value of European Companies; Working Paper No. 10. Venice: Università Ca'. Available online: http://virgo.unive.it/ wpideas/storage/2013wp10.pdf (accessed on 1 August 2013). 
Curtis, Joyce, Daniel D’Angelo, Matthew Hallowell, Timothy Henkel, and Keith Molenaar. 2012. Enterprise risk management for transportation agencies. Transportation Research Record, 57-65. [CrossRef]

Czajkowska, Agnieszka, and Renata Stasiak-Betlejewska. 2016. Determinants of the machining process in the steel industry. Paper presented at METAL 2016-25th Anniversary International Conference on Metallurgy and Materials, Brno, Czech Republic, May 25-27; pp. 1763-68.

Enders, Christian, Gabriele Elisabeth Lang, Gerhard Klaus Lang, and Jens Ulrich Werner. 2017. ISO 9001:2015 Certification in Quality Management I [Zertifizierung des Qualitätsmanagements nach DIN EN ISO 9001:2015]. Klinische Monatsblatter fur Augenheilkunde 234: 886-90. [CrossRef] [PubMed]

Finnveden, Göran, Michael Zwicky Hauschild, Tomas Ekvall, Jeroen Guinee, Reinout Heijungs, Stefanie Hellweg, Annette Koehler, David Pennington, and Sangwon Suh. 2009. Recent developments in Life Cycle Assessment. Journal of Environmental Management 91: 1-21. [CrossRef]

Ghasemi, Meysam, and Majid Ghasemi. 2020. Investigating the relationship between working capital management strategies and risk management for companies listed on the Tehran stock exchange. Journal of Critical Reviews 7: 474-83. [CrossRef]

Goncharenko, Ludmila P., Sergey Alexandrovich Filin, and E.E. Nalesnaya. 2016. Strategic risk management in innovative metallurgical investment. Steel in Translation 46: 42-44. [CrossRef]

GOST R ISO 9001. 2015. Quality Management Systems—Requirements. Moscow: Standartinform, 32p.

GOST R ISO/IEC 31010. 2012. Risk Management_Risk Assessment Techniques. Moscow: Standartinform, 74p.

Healy, Teleah Joy, Nicholas James Hill, Andrew Chin, and Adam Barnett. 2020. A global review of elasmobranch tourism activities, management and risk. Marine Policy 118: 103964. [CrossRef]

Ionova, E. I., and Nelli Vladimirovna Syreyshchikova. 2019. Developing of an optimal download model ofrolling mills. Yekaterinburg. UGLTU, 389-92. Available online: https:/ / elar.usfeu.ru/handle/123456789/8702 (accessed on 23 June 2021).

ISO 22000:2018. 2018. Food Safety Management Systems—Requirements for Any Organization in the Food Chain. Moscow: OOO “InterKonsalt", $18 \mathrm{p}$.

Kazakova, Nataliya, and Vera Gennadievna Kogdenko. 2021. Methods of research of environmental risks of largest Russian companies of ferrous metallurgy. Chernye Metally 2021: 69-75. [CrossRef]

Kondratyeva, O. V., O. A. Kondratyeva, and I. A. Kondratev. 2021. The Risk Management Methodology of the Quality Reducing Process of Enterprise Management Information Systems Service Support. Paper presented at IOP Conference Series: Earth and Environmental Science, International Science and Technology Conference "Earth Science", Vladivostok, Russian Federation, December 8-10; Vol. 666, p. 062128. [CrossRef]

Lee, Jaesang, Shaily Mahendra, and Pedro J.J. Alvarez. 2010. Nanomaterials in the construction industry: A review of their applications and environmental health and safety considerations. ACS Nano 4: 3580-90. [CrossRef] [PubMed]

Małysa, Tomasz, Krzysztof Nowacki, and Joanna Furman. 2016. The risk management methodology in the metallurgical enterprise. Paper presented at METAL 2016 - 25th Anniversary International Conference on Metallurgy and Materials, Brno, Czech Republic, May 25-27; pp. 1925-30.

Mamaeva, L. N. 2013. Risk Management. Moscow: Dashkov i K, 139p.

Markowitz, Harry. 1952. Portfolio Selection. The Journal of Finance 7: 77-91. [CrossRef]

Mills, Anthony. 2021. A systematic approach to risk management for construction. Structural Survey 19: 245-52. [CrossRef]

Padanyi, A. 1971. Insurance for the industry. AACE Bul 13: 16-20.

Ponomarev, S. V. 2016. Practical Approaches to Risk Assessment in the QMS. Methods of Quality Management 7: 46-51.

Prakash, Surya, Gunjan Soni, and Ajay Pal Singh Rathore. 2017. A critical analysis of supply chain risk management content: A structured literature review. Journal of Advances in Management Research 14: 69-90. [CrossRef]

Prata, Emille Rocha Bernardino de Almeida, José Benício Paes Chaves, Silvane Guimarães Silva Gomes, and Frederico José Vieira Passos. 2020. Statistical quality control in the food industry: A risk-based approach. International Journal of Quality and Reliability Management 38: 437-52. [CrossRef]

Razuvaev, Vladimir Vitalievich. 2016. Specificity of Risks in Russian Metallurgy//Economics and Management of Innovative Technologies. No. 2 [Electronic Resource]. Available online: https://ekonomika.snauka.ru/2016/02/10880 (accessed on 23 June 2021).

Samson, Danny A. 1987. Corporate risk philosophy for improved risk management. Journal of Business Research 15: 107-22. [CrossRef]

Schumpeter, Joseph A., Richard V. Clemence, and Richard Swedberg. 2017. Essays: On Entrepreneurs, Innovations, Business Cycles and the Evolution of Capitalism. New York: Routledge, pp. 1-341. [CrossRef]

Scott, Susan, and Nicholas Perry. 2012. The enactment of risk categories: The role of information systems in organizing and re-organizing risk management practices in the energy industry. Information Systems Frontiers 14: 125-41. [CrossRef]

Shojaei, Payam, and Seyed Amin Haeri. 2019. Development of supply chain risk management approaches for construction projects: A grounded theory approach. Computers and Industrial Engineering 128: 837-50. [CrossRef]

Siferd, Sue Perrott, and Larry R. Smeltzer. 1998. Risk assessment in the supply chain. Proceedings—Annual Meeting of the Decision Sciences Institute 3: 1476.

Syreyshchikova, Nelli Vladimirovna, Danil Yurievich Pimenov, Angelos P. Markopoulos, and Liviu Moldovan. 2021a. Value Stream Maps in Clock Production. Russian Engineering Research 41: 378-81. [CrossRef] 
Syreyshchikova, Nelli Vladimirovna, Danil Yurievich Pimenov, Irina A. Kulygina, and Liviu Moldovan. 2021b. Hybrid Model for Calculating Quality Costs. Russian Engineering Research 41: 382-86. [CrossRef]

Syreyshchikova, Nelli Vladimirovna, Danil Yurievich Pimenov, Tadeusz Mikolajczyk, and Liviu Moldovan. 2019. Information Safety Process Development According to ISO 27001 for an Industrial Enterprise. Procedia Manufacturing 32: 278-85. [CrossRef]

Syreyshchikova, Nelli Vladimirovna, Danil Yurievich Pimenov, Tadeusz Mikolajczyk, and Liviu Moldovan. 2020a. Automation of production activities of an industrial enterprise based on the ERP system. Procedia Manufacturing 46: 525-32. [CrossRef]

Syreyshchikova, Nelli Vladimirovna, Danil Yurievich Pimenov, Tadeusz Mikolajczyk, and Liviu Moldovan. 2020b. Development of a risk management technique in strategic planning of universities. Case study of a Polytechnical Institute. Procedia Manufacturing 46: 256-62. [CrossRef]

Tayal, Ashwani, Nirmal S. Kalsi, Munish Kumar Gupta, Danil Yurievich Pimenov, Murat Sarikaya, and Catalin I. Pruncu. 2021. Effectiveness Improvement in Manufacturing Industry; Trilogy Study and Open Innovation Dynamics. Journal of Open Innovation: Technology, Market, and Complexity 7: 7. [CrossRef]

Ulven, Joachim Bjørge, and Gaute Wangen. 2021. A systematic review of cybersecurity risks in higher education. Future Internet 13: 39. [CrossRef]

Uuskoski, Mikko, Hannu Kärkkäinen, and Karan Menon. 2020. Rapid Sales Growth Mechanisms and Profitability for Investment Product Manufacturing SMEs Through Pay-Per-X Business Models. IFIP Advances in Information and Communication Technology 594: 402-15. [CrossRef]

Veena, T. R., and G. V. Prabhushankar. 2019. A literature review on lean, Six Sigma and ISO 9001:2015 in manufacturing industry to improve process performance. International Journal of Business and Systems Research 13: 162-80. [CrossRef]

Verma, Devesh, and Kingshuk K. Sinha. 2020. Toward a theory of project interdependencies in high tech R \& D environments. Journal of Operations Management 20: 451-68. [CrossRef] 